\title{
RADAR DA EMBALAGEM: UMA REFERÊNCIA PRELIMINAR PARA O PROJETO DE EMBALAGEM EM UM CONTEXTO SISTÊMICO E DE COMPLEXIDADE
}

Ricardo Marques Sastre (ricsastre@gmail.com) - Programa de Pós Graduação em Engenharia de Produção, Universidade Federal do Rio Grande do Sul - UFRGS.

Istefani Carísio de Paula (istefani@ producao.ufrgs.br) - Programa de Pós Graduação em Engenharia de Produção, Universidade Federal do Rio Grande do Sul - UFRGS.

Marcia Elisa Soares Echeveste (echeveste@ producao.ufrgs.br) - Programa de Pós Graduação em Engenharia de Produção, Universidade Federal do Rio Grande do Sul - UFRGS.

Cristiane Ferrari Zeni (ferrarizeni@gmail.com) - Universidade Federal do Rio Grande do Sul - UFRGS.

\section{RESUMO}

Embalagens são invólucros que têm como funções primárias conter, proteger e transportar mercadorias, são complexas e sistêmicas, se consideradas ao longo do seu ciclo de vida (CV). $\mathrm{O}$ estudo tem por objetivo gerar uma base referencial sobre a qual o projetista possa refletir e explorar cenários durante a concepção do projeto estrutural e gráfico da embalagem. $\mathrm{O}$ conteúdo que suporta a base referencial proposta "Radar da Embalagem", tem sido compilado ao longo de anos de investigação do autor principal sobre o tema, visto que este está disperso em diferentes fontes e áreas de conhecimento. Esta pesquisa é de natureza qualitativa e utilizase da análise de conteúdo e opinião especializada. A unidade de contexto usada na concepção do radar da embalagem foi o seu CV. As unidades de análise incluíram diretrizes ambientais, stakeholders envolvidos em cada fase do $\mathrm{CV}$, materiais e processos, tipos de classificação e funções da embalagem. A proposição do radar da embalagem, mesmo em versão preliminar, mostra seu potencial para o diagnóstico e melhoria de projetos existentes, na classificação de embalagens, no desenvolvimento de embalagens sustentáveis, em atividades de ensino e de formação de profissionais da embalagem, nos cursos técnicos e superiores que possuem esta disciplina.

Palavras chave: projeto de embalagem; referência; design de embalagem; ciclo de vida 


\section{INTRODUÇÃO}

Embalagens são invólucros, recipientes ou qualquer forma de acondicionamento removível ou não, destinados a cobrir, empacotar, envasar, proteger, manter os produtos ou facilitar a sua comercialização. A embalagem é um sistema cuja função é técnica e comercial e tem como objetivos acondicionar, proteger (desde o processo de produção até o consumo), informar, identificar, promover e vender um produto. A embalagem é o elemento que protege o que vende, além de vender o que protege. Embalar não é apenas envolver o conteúdo de forma segura, mas também dosá-lo e levá-lo ao consumidor em uma unidade prática. A embalagem que se encontra em supermercados e lojas é o resultado da ação de um sistema complexo e multidisciplinar, resultante da atuação de diversos especialistas que desenvolvem atividades complementares, tais como pesquisadores, designers, operadores, dentre outros envolvidos em sua concepção. (Gurgel, 2007; Mestriner,2007; Moura \& Banzato, 1997; Negrão, 2008).

Os projetistas, no entanto, para o cumprimento do prazo de entrega e das demandas dos clientes (Briefing), nem sempre levam em consideração um olhar sistêmico do processo, imprescindível em um ambiente de economia circular. $\mathrm{O}$ resultado são embalagens que se convertem facilmente em resíduos, os quais têm impactado negativamente o meio ambiente. As embalagens estão presentes na sociedade desde o dia em que se percebeu a necessidade de proteger, conter e transportar mercadorias. Inicialmente, conforme relata Cavalcanti (2006), o homem começou a lançar mão das folhas de plantas, do couro e da bexiga de animais como matéria-prima de embalagem. Após, adotou novas tecnologias, como a cerâmica, vidro, tecido, madeira, papel, aço e plásticos (PP, PET, PE, dentre outros). Segundo Mestriner (2002), a vida nas grandes metrópoles na atualidade não seria possível sem a utilização intensiva de embalagens para prover o abastecimento de víveres e o consumo de seus milhões de habitantes. Com o desenvolvimento do mercado consumidor, as embalagens foram agregando importância e as funções primárias foram ampliadas em consequência do autosserviço. Sendo a embalagem parte integrante do produto, na maioria dos casos, o consumidor não dissocia o produto da embalagem, tornando-se indispensável um aprofundamento maior sobre o tema (Mestriner, 2002).

Segundo Cavalcanti, (2006) qualidades antigas, como a resistência ao transporte e à umidade, continuam essenciais, mas obrigatoriamente suplementadas por outras também importantes, como a identificação do fabricante do produto embalado e o poder de sedução exercido sobre os compradores. O que era um simples envoltório anônimo se transformou em 
um instrumento de propaganda e marketing no ponto de venda, especialmente para os gestores de pequenos e médios empreendimentos. Segundo o SEBRAE, no Brasil existem 6,4 milhões de estabelecimentos e desse total, 99\% são micro e pequenas empresas (MPE). As MPEs respondem por $52 \%$ dos empregos com carteira assinada no setor privado ( 16,1 milhões) e a maioria, não dispõe de somas significativas para investir em marketing.

Considera-se que a embalagem passa por constantes melhorias nos processos produtivos e no aperfeiçoamento de novas matérias-primas obtidas através da mistura de materiais e principalmente pelo seu design. É importante para o profissional responsável pelo desenvolvimento de embalagens (projetista), levar em considerações os aspectos de sustentabilidade em seus projetos, visto que ela também tem sido vista como grande vilã, impactando os ecossistemas, sempre que é mal projetada e descartada inadequadamente pelo usuário, esteja este usuário em qualquer ponto do ciclo de vida da embalagem (Brod Jr., 2004; Calver, 2009; Mestriner, 2018; Negrão, 2008; Peltier, 2009).

Sob o ponto de vista de conhecimento, a embalagem não é propriedade de uma área em especial. Cursos de design costumam ter disciplinas que preparam profissionais projetistas, mas ela também é conteúdo de cursos como engenharia de alimentos, engenharia de materiais, farmácia, logística e outros. Cada área de conhecimento explora seus aspectos mais relevantes como: os tipos de materiais de sua composição e incompatibilidade com alimentos e medicamentos, métodos de design, processo criativo e atratividade para o consumidor, (Howard, Nicholas \& Loyd, 2000; Le Hir, 1997; Collaro, 2015; Moore, 2010; Carvalho, 2008). De fato, boa parte destes conteúdos estão consolidados em livros, artigos e bases não acadêmicas como sites de entidades de classe, como a ABRE (Associação Brasileira de Embalagens; ABTG (Associação Brasileira de Tecnologia Gráfica; Instituto de embalagem; Revista Pack; Embanews, dentre outros). Esta realidade impõe sobre o profissional interessado no tema uma volta olímpica na literatura acadêmica e não acadêmica, que nem sempre é de fácil acesso e análise. Diante deste cenário, o presente estudo tem por objetivo compilar o conhecimento e gerar uma base referencial sobre a qual o projetista possa refletir e explorar cenários durante a concepção do projeto estrutural e gráfico da embalagem.

O conteúdo teórico que dá suporte à base referencial proposta e que foi denominada de "Radar da Embalagem", tem sido compilado ao longo de anos de investigação do autor sobre o tema, que foi consolidado em algumas de suas publicações (Sastre, 2004; Sastre, 2006; Sastre, 2013; Sastre, 2014; Sastre, 2015; Sastre; 2016; Sastre, 2017; Sastre et al., 2018a; Sastre, et al. 
2018b; Sastre e Echeveste, 2019). Ao longo do tempo, a despeito das tentativas deste autor em gerar uma referência que sintetizasse o conhecimento investigado, os formatos de consolidação escolhidos privilegiavam alguma área em especial, sem prover o benefício e amplitude que o conhecimento exigia. Finalmente, o radar da embalagem consolida este esforço, tendo como unidade de contexto o seu ciclo de vida, elemento que viabilizou a concretização do conteúdo teórico compilado.

Sob o ponto de vista teórico, o Radar da Embalagem permite ao mesmo tempo dar visibilidade sistêmica e síntese de conhecimentos de naturezas distintas, que estavam dispersos, em um único instrumento. Sob o ponto de vista prático, o radar pode será usado em: melhorias de projetos existentes e na classificação de embalagens; na ação criativa para o desenvolvimento de embalagens sustentáveis; em atividades de ensino e de formação de profissionais da embalagem, nos cursos técnicos e superiores que possuem esta disciplina, tais como: design, engenharia de alimentos, logística, dentre outros.

\section{REVISÃO TEÓRICA}

A análise da literatura relativa ao tema embalagem permite segregar algumas categorias de informação que são frequentemente citadas em diferentes fontes. Optou-se por apresentar algumas neste referencial teórico, em virtude da importância que adquiriu na análise de conteúdo. Diferente dos novos tipos de materiais e tecnologias usadas em embalagens que pertencem à fronteira do conhecimento e estão publicados em artigos acadêmicos de journals de relevância, as informações deste referencial teórico são conhecimentos já consolidados pelo uso e estão disponíveis em livros técnicos. Assim, as fontes utilizadas neste referencial teórico foram extraídas em sua maioria em livros e materiais compilados por entidades de classe ligadas ao tema que têm curadoria técnica de seus conteúdos por se destinarem a profissionais da área.

\subsection{Ciclo de vida}

As embalagens, como qualquer produto, apresentam um ciclo de vida e o seu processo de desenvolvimento deve considerar a integridade do produto, a satisfação dos consumidores e o meio ambiente. O processo inicia com a extração da matéria-prima na natureza e sua posterior transformação em papel nas fábricas de beneficiamento. A terceira etapa é onde é feita a concepção da embalagem (estrutural e gráfica) por meio de um estúdio ou agência de design que dará o encaminhamento para a indústria gráfica. Após, a produção das embalagens, ocorre 
o envase e a distribuição para os pontos de venda, deixando-a a disposição do consumidor para a utilização. Por fim, ocorre o descarte das embalagens, o tratamento e triagem. Estas etapas proporcionam o retorno da embalagem para as fábricas de papel através da reciclagem (Peltier, 2009; Bohlmann 2004; Bridgens, 2018; Zampori, 2013).

\subsection{Funções}

Ao longo dos últimos anos, inúmeras funções foram agregadas à embalagem. Das funções primárias - que compreendem conter, proteger, transportar e expor (Gurgel, 2007; Moura \& Banzato, 1997; Negrão, 2008). Foram acrescidas outras funções, tais como: de venda, promoção de vendas e suporte para ações de marketing, suporte para branding, dentre outras, (Calver, 2009; Mestriner, 2018; Coles, 2004). Segundo os autores mencionados, isto se deve fundamentalmente às mudanças no modo de vida na sociedade contemporânea. Questões de ordem econômica, tecnológica, mercadológica, comunicacional e de meio ambiente somaramse às preocupações de ordem primária. Para Gurgel (2007), a embalagem exerce a função de comunicação do conceito mercadológico do produto. A embalagem deve chamar a atenção no ponto de venda e despertar o desejo de compra. Segundo Mestriner (2002), ela é um componente na formação de preço de um produto tornando-se matéria-prima para a indústria que a utiliza para embalar seu produto. Para manter esta integridade do produto, novas tecnologias como a mistura de materiais e a concepção de matérias-primas sustentáveis, surgem para auxiliar no acondicionamento, utilizando materiais sofisticados e métodos de produção diferenciados que resultam na maior conservação dos produtos e possibilitam a expansão do mercado para outros países distantes. A função sociocultural pode ser vista em algumas embalagens através da expressão de uma determinada sociedade, assim como fatos históricos. Por fim, o principal componente do lixo urbano são os resíduos orgânicos, mas a embalagem aparece como o item de maior visibilidade (Mestriner, 2002). Desenhar de forma consciente observando todo o ciclo de vida da embalagem, atualmente, é obrigação do profissional responsável pelo projeto.

\subsection{Classificação}

As embalagens, de uma forma geral, são classificadas nos seguintes tipos, segundo 
Carvalho (2008), em primárias, secundárias e terciárias, figura 1.

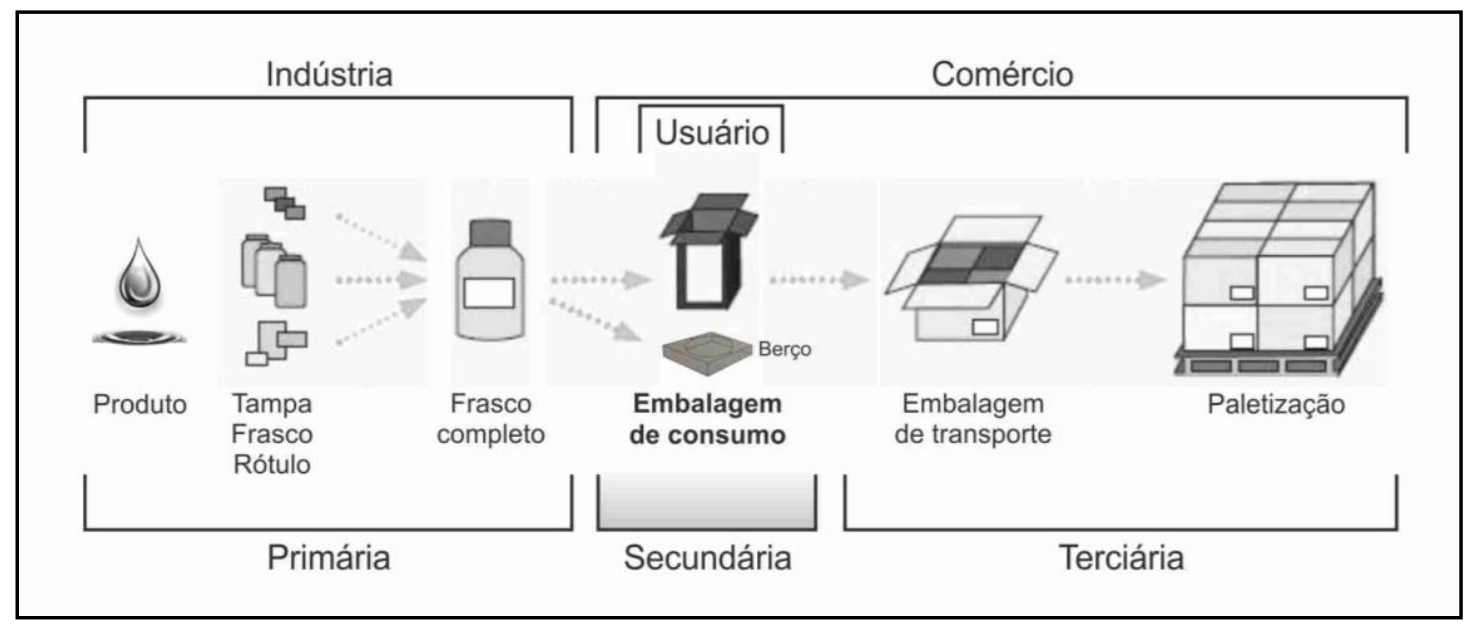

FIGURA 1 - Classificação das embalagens. Fonte: Adaptado de Carvalho (2008).

As primárias são aquelas utilizadas pela indústria no envase do produto, (tampa, frasco e rótulo). As embalagens secundárias são as embalagens de consumo, aquelas que estão em contato com o usuário e expostas no ponto de venda. As embalagens de transporte são as terciárias e contém de forma organizada todos os elementos anteriores, (Howard, Nicholas \& Loyd, 2000; Le Hir, 1997; Collaro, 2015; Moura \& Banzato, 1997; Carvalho, 2008). Por uma questão de segurança e manutenção da integridade do produto, pode-se adotar um berço dentro das embalagens de consumo para certificar que no transporte o frasco não sofrerá nenhuma avaria. Em alguns casos, a embalagem de transporte serve como embalagem de consumo, isso ocorre em produtos maiores, como eletrodomésticos e máquinas. Ampliando esta classificação apresenta-se as embalagens de quarto nível ou contenedores, que facilitam a movimentação e armazenagem e as de quinto nível, utilizadas para envio de longa distância, como os containers (Moura e Banzato, 1997).

\subsection{Materiais e processos}

Os processos de fabricação de embalagens dividem-se na sua concepção formal e em processos de impressão, variando de acordo com o tipo de matéria-prima utilizada. Uma das premissas básicas para o desenvolvimento de um projeto de embalagem é compreender seu processo de fabricação e a viabilidade do projeto. Devido a diversidade de materiais e métodos disponíveis, esta tarefa torna-se complexa e primordial neste processo. Segundo Moura e Banzato (1997) a escolha do tipo de embalagem baseia-se fundamentalmente, no conhecimento 
do material que a construirá, suas características e suas propriedades, levando-se em consideração as necessidades do produto, fabricação, distribuição física e cliente final. Os vários processamentos de um material determinam as possibilidades formais que uma embalagem poderá assumir. Os principais materiais utilizados na fabricação de embalagens são: a madeira, o papel, o metal, o plástico e o vidro. Novos materiais como as embalagens feitas por multicamadas, bem como a concepção de materiais sustentáveis como polímeros produzidos a partir de fontes vegetais e/ou reaproveitamento de resíduos são novidades constantes no setor de embalagens.

Sobre os processos de impressão, segundo Fernandes (2003), são meios de produção capazes de realizar uma ou diversas cópias de determinada imagem. As impressões que utilizam tintas podem necessitar de matrizes ou não. As que não utilizam matrizes são as impressões digitais que podem ser jatos de tinta, eletrostática, também conhecidas como impressão a laser. Segundo Baer (1999), a maioria dos processos de impressão utilizam matrizes em sua produção e são subdivididas pela característica das formas. Relevográficas - são as matrizes que possuem relevo como o clichê para a flexografia e os tipos móveis na tipografia, utilizados em embalagens plásticas flexíveis. Planográficas - são as formas planas como as da impressão litográfica que utilizava uma pedra como matriz e a impressão offset, que utiliza uma chapa de alumínio, utilizadas para embalagens de papel. Encavográficas - são matrizes feitas com entalhe como o cilindro de rotogravura e o silicone da tampografia, geralmente para tiragens maiores. Permeográficas - são formas que a tinta penetra e ultrapassa para o papel como a serigrafia, para a impressão direta em potes, por exemplo.

\subsection{Diretrizes ambientais}

A sustentabilidade ambiental refere-se às condições sistêmicas a partir das quais as atividades humanas, em escala mundial ou em escala local, não perturbem os ciclos naturais, além dos limites de resiliência (capacidade de tolerar uma atividade que o perturba sem perder irreversivelmente seu equilíbrio) dos ecossistemas nos quais são baseados e, ao mesmo tempo, não empobreçam o capital natural que será herdado pelas gerações futuras. O conceito de embalagem sustentável está diretamente relacionado à minimização do impacto ambiental, assim o olhar para o ciclo de vida torna-se fundamental (Manzini, 2008; Pereira, 2012). A Associação Brasileira de Embalagem - ABRE, considerada a mais importante e representativa entidade de classe do setor no Brasil, em seu comitê de estudos avançados em meio ambiente e 
sustentabilidade propôs os indicadores ambientais de auto-avaliação da indústria para melhoria contínua. Estes indicadores estão contidos em uma planilha e estão relacionados a cada etapa do ciclo de vida da embalagem.

\section{METODOLOGIA}

Esta pesquisa é de natureza qualitativa e utiliza-se a técnica de análise de conteúdo composta por três macro etapas destacadas como essenciais desta metodologia, sugeridas por Bardin (1977) e Moraes (1999), e adaptada pelos autores do presente estudo. Participaram da construção do radar da embalagem dois profissionais da área do design. Outros três profissionais, um especialista em embalagem com 23 anos de experiência e dois especialistas em gestão do desenvolvimento de produto com mais de 20 anos de experiência cada, foram consultados na avaliação dos resultados de cada etapa.

01) Categorização: é um procedimento de agrupar dados, considerando a parte comum existente entre eles. Classifica-se por semelhança ou analogia, segundo critérios previamente estabelecidos ou definidos no processo. A categorização é uma operação de classificação dos elementos de uma mensagem, seguindo determinados critérios, facilitando a análise das informações (Moraes, 1999). Parte do conteúdo compilado faz parte do acervo pessoal do autor principal deste artigo, que tem estudado embalagens ao longo de 23 anos. O material foi ampliado por buscas de artigos em bases de dados como EBSCO, Emerald, Science Direct, Springer, Web of Science e Willey. Foi utilizado como palavras chave para as buscas e operadores boleanos "pack*" and "sustainab*" and "eco". Os artigos confirmaram os conhecimentos consolidados nos livros, e eventualmente, adicionaram novos materiais e técnicas da fronteira do conhecimento. Também fizeram parte do conteúdo compilado, as versões gráficas de referências que sintetizassem o conhecimento investigado em formatos de consolidação do tipo tabela; processo; listas; mapa mentais, elaboradas ao longo do tempo pelo autor principal deste trabalho. Dois profissionais da área de design realizaram a compilação e organização destes conteúdos, além da investigação através de um artigo denominado embalagens sustentáveis: o estado da arte da produção de teses e dissertações nos cursos de pós graduação em design, publicado pelos autores no $13^{\circ}$ congresso brasileiro de pesquisa em Desing, o P\&D (Sastre et al., 2018a). 
02) Descrição: uma vez definidas as categorias e identificando o material constituinte de cada uma delas é preciso comunicar o resultado deste trabalho. A descrição é o primeiro momento desta comunicação. De modo geral, a organização desta descrição será determinada pelo sistema de categorias construído ao longo da análise. Este é o momento de expressar os significados captados e intuídos nas mensagens analisadas (Moraes, 1999). Para a etapa de descrição os autores definiram como unidade de contexto "ciclo de vida" do produto embalagem. As unidades de análise emergiram naturalmente do conteúdo analisado e são elas: funções, classificação, materiais e processos, stakeholders ${ }^{1}$ e indicadores ambientais.

03) Interpretação: esta etapa procura atingir uma compreensão mais aprofundada do conteúdo das mensagens através da interpretação. A análise de conteúdo exercita com maior profundidade este esforço de interpretação e o faz não só sobre conteúdos manifestos pelos autores, como também sobre os latentes (captação de sentidos implícitos). A teoria é construída com base nos dados e nas categorias de análise. A base teórica emerge das informações e das categorias, neste sentido, a própria construção da teoria é uma interpretação (Bardin, 1977; Moraes, 1999). Nesta etapa foram elaboradas versões do radar que foram submetidas à análise crítica do especialista em embalagem e dos especialistas em gestão do desenvolvimento de produtos. Alterações foram sendo realizadas, para gerar a versão final do artefato.

\section{RESULTADOS E DISCUSSÃO}

Nesta etapa, apresentam-se os resultados da compilação teórica relacionadas a embalagem, denominado Radar da Embalagem. As dimensões de conteúdo do Radar foram compostas por meio de pesquisa em diversas fontes, provenientes de diferentes áreas de conhecimento indicados no quadro 1.

\begin{tabular}{|l|c|c|c|c|c|c|}
\hline $\begin{array}{l}\text { Fontes/áreas de } \\
\text { conhecimento }\end{array}$ & Design & Engenharias & Farmácia & Administração & Química & Direito \\
\hline Normas & & $\mathrm{X}$ & $\mathrm{X}$ & & & $\mathrm{X}$ \\
\hline Livros & $\mathrm{X}$ & $\mathrm{X}$ & $\mathrm{X}$ & $\mathrm{X}$ & & \\
\hline Artigos & $\mathrm{X}$ & $\mathrm{X}$ & $\mathrm{X}$ & $\mathrm{X}$ & $\mathrm{X}$ & \\
\hline Sites & $\mathrm{X}$ & & & & & \\
\hline Instituições & $\mathrm{X}$ & $\mathrm{X}$ & & $\mathrm{X}$ & & $\mathrm{X}$ \\
\hline
\end{tabular}

1 Segundo o PMI (2017) stakeholders são as partes interessadas (pessoas e organizações), como clientes, patrocinadores, organizações executoras e o público, que estejam ativamente envolvidos no projeto ou cujos interesses possam ser afetados de forma positiva ou negativa pela execução ou término do projeto, podendo exercer influência sobre o projeto e suas entregas. 
QUADRO 1 - Dimensões de conteúdo do Radar da Embalagem. Fonte: Os autores

O Radar da embalagem foi sendo construído ao longo de diversas iterações (realizada em anos), assumindo diferentes formatos. Inicialmente foi concebido como uma tabela para agrupar as informações relevantes sobre a embalagem. A tabela foi convertida em uma matriz visando identificar correlações entre os conteúdos, mas ainda difícil de expressar os níveis de interações entre as dimensões. A matriz evoluiu, posteriormente para dois mapas mentais (Figura 2). O primeiro permitiu acumular um grande volume de informações sobre a embalagem, porém sem nenhuma interação entre as dimensões. O mapa versão 2 trouxe maior grau de organização lógica, usando as etapas do ciclo de vida, porém em formato linear.

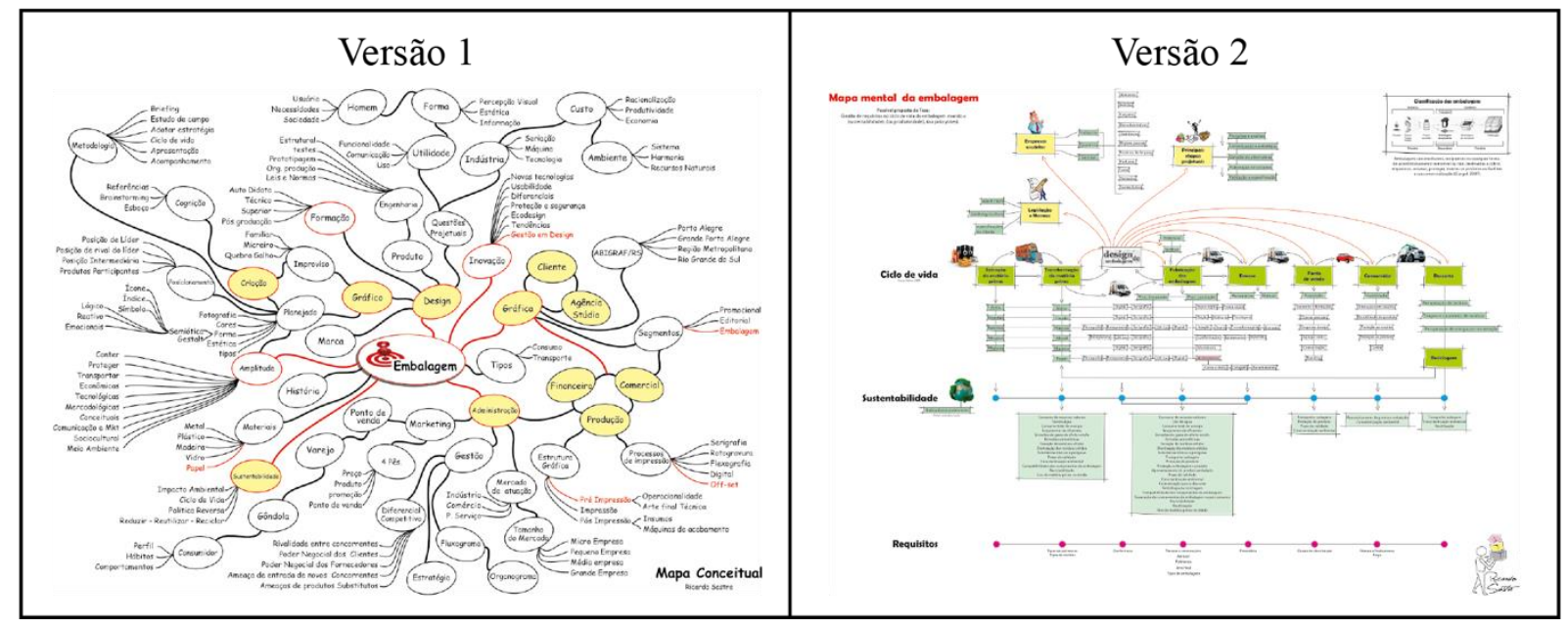

Figura 2 - Mapas mentais. Fonte: Os autores

Ambos mapas mentais dificultavam a interação entre as dimensões de análise, no entanto a representação linear continha como elemento contextual o ciclo de vida, que naturalmente remetia à circularidade, por conta da retroalimentação do sistema. Assim, surgiu a versão circular, denominada, portanto, de radar, desta vez agrupando as dimensões com legibilidade e permitindo interações entre as suas dimensões de conteúdo. Entende-se por interação a possibilidade de visualização de combinações entre estas dimensões durante o processo criativo ou de análise da embalagem.

01 Categorização: As categorias propostas emergiram do referencial teórico e foram divididas em unidade de contexto e unidade de análise. O processo de categorização deve ser entendido em sua essência como um processo de redução de dados.

Na unidade de contexto encontra-se o ciclo de vida da embalagem, ou seja, o ponto de partida do radar. Localizado no centro do radar, ele é composto por oito fases determinantes 
para a divisão das categorias propostas. Através do ciclo de vida foi possível alcançar uma homogeneidade nas temáticas, envolvendo os aspectos determinantes na construção ou análise de uma embalagem, seu agrupamento foi possível dentro das etapas do ciclo de vida e também nas relações entre elas.

$\mathrm{Na}$ unidade de análise, apresenta-se as seis categorias propostas que foram dispostas radialmente, do centro para as bordas, obedecendo uma sequência por ordem de importância na construção e análise de uma embalagem, são elas: funções da embalagem; classificação; materiais e processos; stakeholders (partes interessadas) e diretrizes ambientais.

02 Descrição: nesta etapa descrevem-se as dimensões contidas no radar da embalagem aplicadas às principais etapas projetuais no desenvolvimento de embalagens (Quadro 2).

\begin{tabular}{|l|l|}
\hline Fases projetuais da embalagem & \multicolumn{1}{c|}{ Dimensões do Radar da Embalagem aplicáveis à etapa projetual } \\
\hline Levantamento de requisitos & Ciclo de vida; stakeholders; \\
\hline Conceituação e estratégia & Funções; Classificação; Stakeholders; Diretrizes ambientais \\
\hline Elaboração de soluções & Projeto estrutural e gráfico (leitura radial) \\
\hline Prototipagem & Materiais e processos \\
\hline Validação & Utilizar o radar como um checklist \\
\hline
\end{tabular}

QUADRO 2 - Relação entre as dimensões do Radar da Embalagem e Fases projetuais. Fonte: Os autores

O Radar da embalagem pode ser utilizado para análise de embalagens existentes (A), para o desenvolvimento de novos projetos (B), ou (C) para analisar/propor combinações inovadoras entre suas dimensões (i.e. funções x materiais x processo). Um exemplo de (C) é o caso da Tetra Pack. A solução integrada para suas embalagens multicamadas, inovadora à sua época, envolveu a combinação das dimensões "matéria-primas", o "projeto estrutural", a "fabricação e envase da embalagem" e a "solução para reciclagem". A solução integrada contou com o envolvimento de diferentes stakeholders. É praticamente impossível descrever as ações do ciclo de vida sem mencionar as partes impactadas ou que impactam em cada uma das etapas do $\mathrm{CV}$, razão pela qual foi incluída entre as dimensões do radar.

03 Interpretação: apresenta-se a estrutura conceitual do radar da embalagem e como deve ser lida pelo usuário. O ponto inicial é o ciclo de vida, por meio dele foi possível organizar as categorias ciclicamente, fazendo a leitura do centro para as bordas (radial) e no sentido horário (Figura 2). Na categoria materiais e processos, sugere-se uma leitura no sentido horário (circunferencial), iniciando na extração da matéria prima até o processo de envase. Somente nesta categoria e neste espaço entre a extração da matéria-prima e envase é possível uma leitura sequencial. Sugere-se também fazer uma leitura cruzada entre as etapas do ciclo de vida, embaralhando as informações com o objetivo de encontrar significados cruzados entre as 
dimensões, o que ocasionalmente pode levar a uma interpretação nova (inovadora) por meio de uma da leitura despretensiosa do radar da embalagem (pensamento lateral criativo).

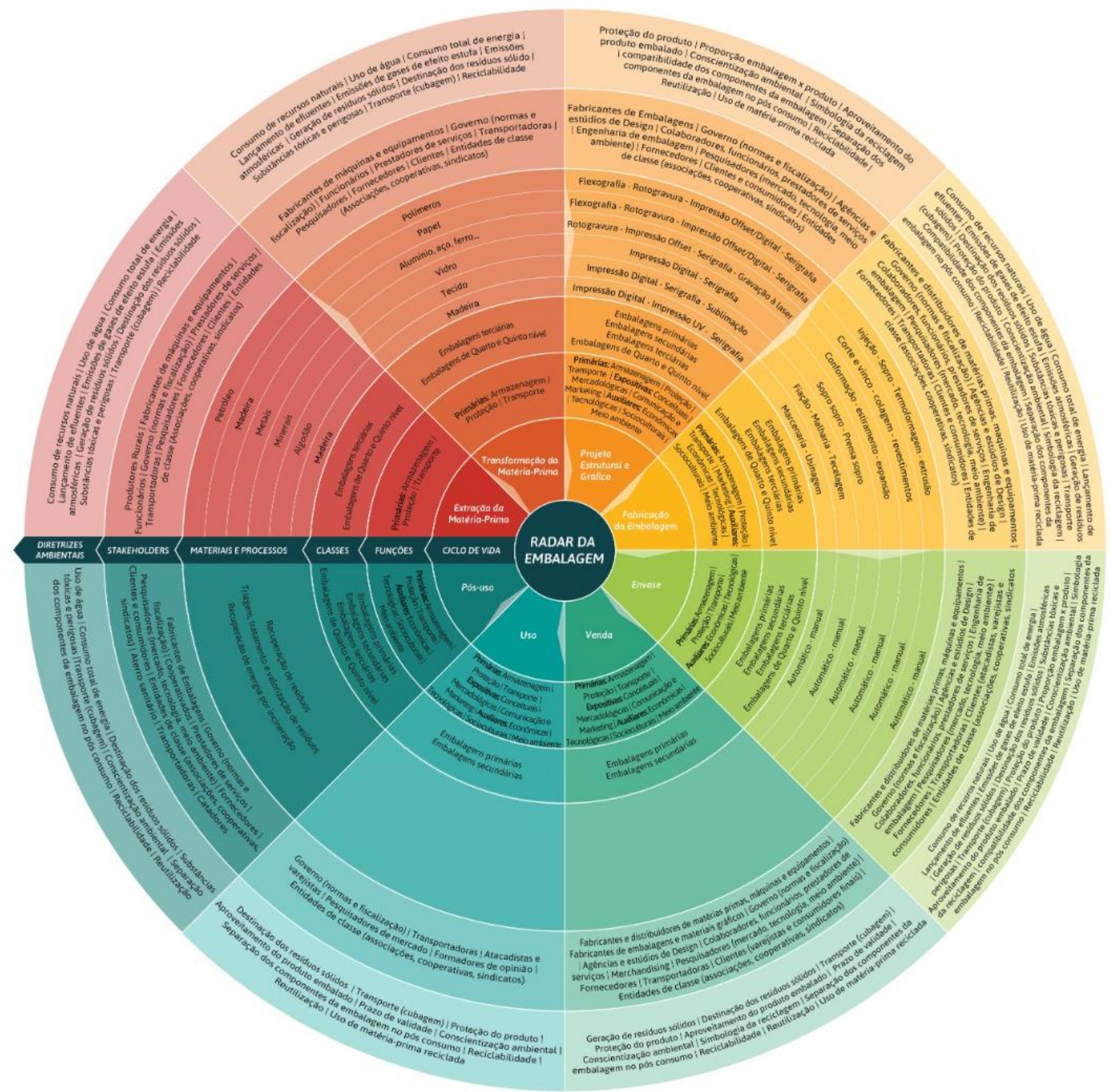

FIGURA 2 - Radar da embalagem. Fonte: Os autores

Os textos estão dispostos no sentido de leitura, não se fazendo necessário mover a folha para lê-lo por inteiro. Em alguns casos, os conteúdos estão presentes em mais de uma fase do ciclo de vida, como o caso dos materiais e processos nas etapas de venda e uso. Em cada etapa do ciclo de vida é ampliado os elementos que compõem a análise, neste sentido, como exemplo, explicita-se na etapa de extração da matéria-prima, suas funções, classificação, materiais e processos, stakeholders e diretrizes ambientais. Cada nível está sobreposto ao outro, permitindo 
ao leitor fazer combinações entre as categorias, por exemplo, na concepção da embalagem, o projetista pode analisar as diretrizes de sustentabilidade em todas as dimensões, bem como testar interações entre elas.

\section{CONSIDERAÇÕES FINAIS}

A percepção do valor trazida pelo radar da embalagem proposto neste trabalho será mais concreta a um leitor ou profissional afeitos a complexidade que representa o universo do projeto de uma embalagem. A amplitude e profundidade do tema podem ser percebidos pela diversidade de autores e fontes citadas ao longo da sua construção. Sob o ponto de vista tanto acadêmico quanto prático, é impensável projetar uma embalagem sem uma reflexão aprofundada nos elementos norteadores de um projeto, apresentados no radar da embalagem.

Pressupõe-se que todo o resíduo gerado pela embalagem é um erro de design, isto é, um projeto que não contemplou as etapas do ciclo de vida e suas interações. A embalagem é considerada multidisciplinar por envolver diversas áreas do conhecimento, tais como: engenharias, design, comunicação, direito, administração, logística, gestão ambiental, dentre outras. A participação de especialistas no tema embalagem e gestão do processo de desenvolvimento de produtos na concepção do artefato trouxe validade para os constructos gerados. Ainda assim, entende-se que estes deverão ser submetidos a outros profissionais, para fins de verificação de sua robustez em refletir cada dimensão de análise do radar. O número de analistas foi uma limitação desta etapa do trabalho. Também foi uma delimitação neste artigo não apresentar exemplos práticos das aplicações idealizadas para o uso do radar, por exigirem muito espaço descritivo.

Uma importante decorrência deste estudo, foi a reflexão sobre o próprio conceito de embalagem apresentado inicialmente. Devido à sua importância no cenário mundial de sustentabilidade e sua complexidade, se propõe uma ampliação do mesmo, conforme apresentado a seguir pelos autores: "Embalagens são recipientes ou invólucros, que têm como funções primárias conter, proteger e transportar mercadorias, e podem ser classificadas como complexas e sistêmicas, abrangendo interações previsíveis elou inesperadas entre suas partes e processos, devendo, portanto, ser consideradas sob a perspectiva de todo o seu ciclo de vida".

Este estudo limitou-se em apresentar a proposição de um modelo teórico integrativo, não ocasionando em um aprofundamento dos elementos do radar, tais como a análise de stakeholders, discussão sobre as diretrizes de sustentabilidade, detalhamento sobre os materiais 
e novos materiais, processos de impressão e fabricação de embalagens, suas funções e classificação. Sugere-se como estudos futuros no âmbito da teoria, uma aproximação do radar da embalagem aos métodos de desenvolvimento de produto, desenvolvimento de serviço, sistema produto serviço, dentre outros. Recomenda-se como aplicação prática, que projetistas envolvidos com a embalagem consultem o radar antes de executarem seus projetos objetivando atender às demandas de toda sua cadeia.

\section{REFERÊNCIAS}

ASSOCIAÇÃO BRASILEIRA DE EMBALAGEM - ABRE. Disponível em: <http://www.abre.org.br>. Acesso em: 08 jun. 2019.

BAER, Lorenzo. Produção gráfica. São Paulo: Senac São Paulo, 1999.

BARDIN, Laurence. Análise de conteúdo. Lisboa: Edições 70, 1977.

BOHLMANN, Gregory M. Biodegradable Packaging Life-Cycle Assessment. Published online 29 November 2004 in Wiley InterScience (www.interscience.wiley.com). DOI 10.1002/ep.10053

BRIDGENS, Ben. Creative upcycling: Reconnecting people, materials and place through making. Journal of Cleaner Production. 189 (2018) 145e154.

BROD JR. Desenho de embalagem: projeto mediado por parâmetros ecológicos. Dissertação de mestrado (Mestrado em Engenharia de Produção). Universidade Federal de Santa Maria, Santa Maria. 2004.

CALVER, Giles. O que é design de embalagens? Porto Alegre: Bookman, 2009.

CARVALHO, Maria Aparecida. Engenharia de embalagens: uma abordagem técnica do desenvolvimento de projetos de embalagem. São Paulo: Novatec, 2008.

CAVALCNTI, Pedro. História da embalagem no Brasil. São Paulo: Grifo Projetos Históricos e Editoriais, 2006.

COLLARO, Antonio Celso. Produção visual e gráfica. São Paulo: Summus, 2005.

COLES, Robert. E. Estudos de embalagens para o varejo. São Paulo: Blusher, 2004.

FERNANDES, Amaury. Fundamentos de produção gráfica para quem não é produtor gráfico. Rio de Janeiro: Rubio, 2003.

GIL, Antonio Carlos. Como elaborar projetos de pesquisa. São Paulo: Atlas, 2010.

GURGEL, Floriano do Amaral. Administração da embalagem. São Paulo: Thomson, 2007

HOWARD, NICHOLAS \& LOYD. Farmacotécnica: formas farmacêuticas \& sistemas de liberação de fármacos. São Paulo: Editorial Premier, 2000.

LE HIR, A. Noções de farmácia Galênica. São Paulo: Andrei Editora. 1997. 
MANZINI, Ezio. O desenvolvimento de produtos sustentáveis. São Paulo: Editora da Universidade de São Paulo, 2005.

MESTRINER, Fabio. Design de embalagem: curso básico. São Paulo: Pearson Makron Books, 2002.

MESTRINER, Fabio. Design de embalagem: curso avançado. São Paulo: Pearson Makron Books, 2002.

MESTRINER, Fabio. Gestão estratégica de embalagem. São Paulo: Pearson Prentice Hall, 2007.

MESTRINER, Fabio. Inovação na embalagem. São Paulo: Mbooks, 2018

MOORE, Graham. Nanotecnologias em embalagens. São Paulo: Blusher. 2004..

MORAES, Roque. Análise de conteúdo. Revista Educação, Porto Alegre, v. 22, n. 37, p. 7-32, 1999.

MOURA e BANZATO, Reinaldo e Maurício, Embalagem, unitizacão \& conteinerização. São Paulo: IMAM, 1997.

NEGRÃO, Celso. Design de embalagem: do marketing à produção. São Paulo: Novatec, 2008.

PELTIER, Fabrice. Design sustentável: caminhos virtuosos. São Paulo: Senac, 2009.

PEREIRA, Priscila Zavadil. Proposição de metodologia para o design de embalagem orientada à sustentabilidade. Dissertação de Mestrado (Mestrado em Design). Universidade Federal do Rio Grande do Sul, Porto Alegre, 2012.

PMI. Um guia do conhecimento em gerenciamento de projetos. Guia PMBOK® 6a. ed. - EUA: Project Management Institute, 2017.

SASTRE, R. M. A embalagem como espaço alternativo de propaganda. Monografia de Graduação (Publicidade e Propaganda). Universidade do Vale do Rio dos Sinos. São Leopoldo, 2004.

SASTRE, R. M. A importância da embalagem na formação do mercado de consumo brasileiro. Monografia de Pós-Graduação. PUC/RS. Porto Alegre, 2006

SASTRE, R. M. A inovação na embalagem. Monografia de MBA (MBA em Gestão Empresarial). IBGEN, 2013.

SASTRE, R. M. Embalagem de consumo em papel cartão: Categorias para avaliação da inovação no Design e Produção de embalagens. Dissertação de Mestrado (Mestrado em Design). Centro Universitário Ritter dos Reis, Porto Alegre, 2014.

SASTRE, R. M. A gestão da produção gráfica centrada no design de embalagem. Atitude. V6, p149-163, 2015.

SASTRE, R.M. Análise semiótica comparativa no redesenho de embalagem do café Melitta. Espacios (Caracas). V.37, p21, 2016.

SASTRE, R.M. Design de embalagem: os princípios de Redig na teoria da amplitude de Mestriner. Espacios (Caracas). V.39, p1 - 12, 2017.

SASTRE, R.M. Paula, I. C. Echeveste, M. Design de embalagem: abordagens teóricas do Design sobre inovação. p. 289-30. In: São Paulo: Blucher, 2018a. ISSN 2318-6968, ISBN: cid201DOI 10.5151/cid2017-25 
SASTRE, R. M. Paula I. C., Echeveste, M. proposition of guidelines for assessing innovation in the design and production of paperboard consumer packaging. P. 1957-1968 DOI number: https://doi.org/10.21278/idc.2018.0292. International Design Conference, 2018b

SASTRE R. M. Echeveste, M. Development of Sustainable packages from industrial waste of the footwear sector. Leans Conference, 2019.

SEBRAE. Disponível em: http://www.sebrae.com.br/sites/PortalSebrae/ufs/sp/sebraeaz/pequenos-negocios-emnumeros,12e8794363447510VgnVCM1000004c00210aRCRD. Acesso em: 08 jun. 2019.

ZAMPORI, Luca. . Design of a sustainable packaging in the food sector by applying LCA. Int J Life Cycle Assess DOI 10.1007/s11367-013-0618-9. 2013 